\title{
Método de análise imagética: Cazuza na revista Veja como ícone da Aids na década de 1980 no Brasil
}

Imagetic analysis method: Cazuza as an iconic image for Aids in the 1980's in Brazil

\author{
Margarida Maria Rocha Bernardes ${ }^{1}$ \\ Fernando Rocha Porto ${ }^{2}$ \\ Érick Igor dos Santos ${ }^{3}$ \\ Antonio Marcos Tosoli Gomes ${ }^{4}$
}

\begin{abstract}
RESUMO: Este estudo teve por objetivo demonstrar o uso da análise semiótica em fac-símile como documento de pesquisa e resgate da memória social na temática do HIV/Aids. Utilizou-se uma matriz de análise imagética com quatro itens sobre a capa da revista Veja, de 26 de abril de 1989, com a manchete - "Cazuza - uma vítima da Aids agoniza em praça pública". Os resultados foram contextualizados à imagem símbolo de uma pandemia, por meio de elementos públicos midiáticos correspondentes à década de 1980 no Brasil. As discussões se relacionaram com a atitude pela qual o artista retratado expressa sua posição na mídia frente a síndrome. A reportagem de capa da Veja 1.077, prestes a completar 26 anos, ainda consta no ranking das matérias mais comentadas da história da revista, podendo servir como instrumento para estudos de memória social. Conclui-se que a análise da matriz é ratificada como ferramenta de pesquisa de memória social e documental imagética, podendo ser utilizada em estudos de representação social.
\end{abstract}

Palavras-chave: Cazuza; aids-notícia; imagem eidética; representação social; jornalismo.

ABSTRACT: The present study aims to demonstrate the use of semiotic analysis as a research tool in the field of HIV/aids and to draw attention to HIV/Aids in social memory. We used an image analysis matrix with four items on the cover of Veja magazine from the April 26, 1989 that had the following headline: "Cazuza - an AIDS victim agonizes in public". Results were contextualized as a pandemic through midia public elements corresponding to the 1980's in Brazil. The discussion is related to the way the artist expresses his position on the syndrome in the media. The cover story from issue 1,077 of Veja, about to be 26 -years-old, still ranks as one of the most talked about in the history of the magazine, which renders it appropriate as a toll in social memory studies. In conclusion, the matrix analyses is confirmed as a tool in social memory and imagetic documental research, and can be used in social representation studies.

Keywords: Cazuza; aids-news; eidetic imagery; social representation; journalism.

\section{Introdução}

Eventos ocorridos na década de 1980 no Brasil geraram mudanças significativas em áreas importantes para o desenvolvimento e consolidação das diretrizes que vieram a fazer diferença no comando do país. O regime militar foi finalizado e o processo de redemocratização trouxe, em seu bojo, as primeiras eleições diretas em 1988, a elaboração

\footnotetext{
1 Doutora em Enfermagem; Professora do Curso de Graduação em Enfermagem do Centro Universitário Augusto Motta (UNISUAM) - Rio de Janeiro, RJ, Brasil. E-mail: margarbe@globo.com.

2 Pós-Doutor em Enfermagem; Professor Adjunto da Universidade Federal do Estado do Rio de Janeiro - Rio de Janeiro, RJ, Brasil.

${ }^{3}$ Doutorando em Enfermagem pela Universidade do Estado do Rio de Janeiro; Professor Assistente do Departamento em Enfermagem da Universidade Federal Fluminense - Rio das Ostras, RJ, Brasil.

${ }^{4}$ Pós-Doutor em Enfermagem; Professor Titular da Faculdade de Enfermagem da Universidade do Estado do Rio de Janeiro - Rio de Janeiro; RJ, Brasil.
} 
da carta magna, e a volta ao regime democrático, com o término do controle estatal sobre a produção cultural brasileira. Paralelo a esses acontecimentos políticos de monta, com vestígios da liberação sexual da década de 1970 , surge no país e no mundo, na área da saúde, a descoberta da síndrome, causada pelo Vírus da Imunodeficiência Humana (HIV), a SIDA (ou aids) (Síndrome da Imunodeficiência Adquirida), trazendo na transição do século XX para o XXI, uma nova forma das pessoas viverem, a partir de então com o HIV/Aids.

Após mais de três décadas do surgimento da aids, a síndrome ainda é considerada um grande problema de saúde pública mundial. Dentre as inúmeras patologias infecciosas, ela se sobressai pela sua magnitude, corroborada pelos casos notificados que refletem mudanças quanti/qualitativas do perfil epidemiológico com seu caráter instável, além dos agravos causados às populações (Ministério da Saúde, 2014).

$\mathrm{Na}$ primeira fase da epidemia, de 1980 a 1986, surgiram casos da síndrome nos estados de São Paulo, Rio de Janeiro e outras metrópoles do Sudeste e do Sul, majoritariamente pela transmissão homo/bissexual masculino de escolaridade elevada, receptores de sangue e hemoderivados. A segunda fase, de 1987 a 1991, foi demarcada ainda pela transmissão sanguínea e pelo aumento de números de casos entre usuários de drogas injetáveis e o aparecimento de casos entre heterossexuais, iniciando, nessa fase, o processo simultâneo de pauperização dos usuários e interiorização da epidemia. Na terceira fase, de 1992 até a atualidade, as análises epidemiológicas realizadas apontaram um aumento exponencial do número de casos por exposição heterossexual, com o delineamento para a feminização, interiorização e pauperização da mesma (Ministério da Saúde, 2014).

Os primeiros casos da epidemia no Brasil foram identificados no início da década de 1980, encontrados e registrados predominantemente entre gays adultos, usuários de drogas injetáveis e hemofílicos (Ministério da Saúde, 2014). Em 1982 no Brasil, foram diagnosticados sete clientes homo/bissexuais moradores de São Paulo vivendo com o HIV. Em 1983 um cliente foi diagnosticado no Hospital Universitário Gafrée Guinle (HUGG) (Galvão, 2000). Importante salientar que a evolução da epidemia exige uma reflexão própria, na medida em que expõe um cenário com contradições sociais no qual se desenvolveu a aids no passado e permanece existindo no presente.

As diferentes profissões da área da saúde precisaram se envolver de forma direta nos cuidados às pessoas contaminadas pelo HIV que necessitaram de cuidados hospitalares imediatos.

A enfermagem se fez presente participando de todas as fases da epidemia, uma vez que a profissão tem por objetivo o cuidado às pessoas, desde o estado supostamente sadio até o surgimento de agravos, englobando atividades desde a educação em saúde até intervenções por meio de procedimentos técnicos ao longo do tratamento (Andrade \& Capocci, 2004; Costa, Oliveira \& Formoso, 2012).

O conhecimento pelos enfermeiros das representações sociais do cuidado em saúde e em Enfermagem junto aos que viviam com HIV no recorte temporal estudado é expressivo. Seu saber contribuiu significativamente para a compreensão de três elementos: as relações empreendidas, o processo em si e as condições de trabalho à época. É forçoso, pois, que se reconheça o valor e a influência do cuidar desenvolvido por esses profissionais. Viveram, em meio às particularidades da problemática que os cercava, situações que os expunha a acidentes com materiais perfuro cortantes e ao convívio com as consequências da síndrome, como a degeneração física, o isolamento social e a morte. Entre as diferentes pessoas 
assistidas por esses profissionais, podemos citar um artista com destaque nacional que foi Cazuza, cuja imagem ilustra este estudo.

A aids chegou para Agenor de Miranda Araújo Neto, também conhecido como Cazuza, em 1987, aos 29 anos, estando no apogeu da juventude, da inspiração poética, da fama e da vida. Em 26 de abril de 1989 foi publicada a edição da Revista Veja com a manchete "Cazuza - uma vítima da Aids agoniza em praça pública", analisada neste estudo. Cazuza veio a falecer aos 32 anos em 7 de julho de 1990. A mídia brasileira noticiou este fato desde as especulações iniciais, passando pela fase em que o artista assumiu sua condição de soropositivo e, por fim, a sua morte. Sua imagem adoecida personificava os jovens que viviam com o HIV naquela década, tornando sua figura familiar e associada às complicações advindas da patologia.

Determinada pessoa pode ser evocada por um conjunto de explicações, crenças ou ideias caracterizadas pelas representações sociais que são resultantes da interação social, pelo que são comuns a um determinado grupo de indivíduos (Moscovici, 2012).

Assim, Cazuza explica com sua figura física a contaminação pelo vírus HIV. Ao incorporar e utilizar este fac símile (Figura 5) de fotorreportagem, o estudo procurou utilizar e disponibilizar para outros estudos tal instrumento como ferramenta de memória social associada à aids, tendo em vista que a imagem do artista soropositivo para o HIV, fotografado pela mídia e exposto ao grande público fez emergir luz e trouxe discussões sobre a temática no país. No corpo fotografado do artista adoecido pode-se fazer a projeção da imagem da patologia. Cazuza passa a ser a imagem pública da aids e com essa imagem pode ser recuperada a memória social sobre as pessoas adoecidas no período.

Jodelet (2001) afirma que a assimilação da aids pela mídia e pelos diferentes grupos sociais, antes mesmo que as pesquisas biológicas trouxessem conhecimento científico comprovado sobre a patologia, fez com que duas interpretações fossem difundidas: uma moral e social, e outra, de tipo biológico. Essas interpretações acabaram trazendo danos para as diversas relações estabelecidas na vida das pessoas, causando pensamentos préexistentes que levaram a modificações nas vidas privada e social dos indivíduos.

Ressalta-se que as relações entre a constituição da memória e representações sociais podem vir a ser compreendidas a partir das proposições elaboradas por Sá (2012), que afirma ser possível observar a existência de ocorrência de diferentes instâncias de memória social nas representações, por meio da ancoragem das experiências novas nos conhecimentos preexistentes. Para possibilitar a delimitação do campo, pode-se assumir a memória social, enquanto "memória humana" não sendo simplesmente uma reprodução das experiências passadas e sim uma construção presente feita a partir das passadas, em função da realidade atual apoiada por recursos proporcionados pela sociedade e pela cultura (Sá, 2005).

A partir da problemática exposta, este estudo - no qual estão envolvidas questões da saúde de pessoas soropositivas para o HIV -, objetiva demonstrar o uso da análise semiótica em fac-símile como documento de pesquisa e resgaste da memória social na temática do HIV/Aids.

Ressalta-se que na pesquisa que originou este texto, buscou-se atender às normativas da Resolução 466/12, do Conselho Nacional de Saúde, obtendo aprovação do Comitê de Ética em Pesquisa sob o parecer número 336.546. 


\section{Método}

Trata-se da utilização de uma matriz de análise imagética com quatro itens sobre a capa da revista ilustrada "Veja", de 26 de abril de 1989, com manchete "Cazuza - uma vítima da Aids agoniza em praça pública", dentro de uma pesquisa qualitativa.

A abordagem qualitativa agrega geralmente entrevistas e observação (Bauer, 2000). Cabe ressaltar que tal abordagem não tem como característica principal a descrição quantitativa e/ou numérica dos dados, em vista do vínculo indissociável entre a objetividade e a subjetividade dos participantes, sendo considerada uma dinâmica interativa entre o mundo real e o sujeito (Gil, 2002).

A imagem foi apresentada a 30 enfermeiros que trabalharam em cinco hospitais de referência à época para o tratamento da patologia no Rio de Janeiro, para que a mesma enquanto ferramenta de pesquisa pudesse ter um efeito de indutor da memória social daquele grupo. Diante dessa imagem e de outras onze pré-selecionadas na mídia, puderam ser feitos questionamentos aos sujeitos, resultando em registros das suas falas sobre fatos e pessoas de quem esses profissionais pudessem ter cuidado durante as duas fases da epidemia da aids na cidade, no intuito de trazer da memória desse grupo social os cuidados implementados pela enfermagem carioca. As imagens apresentadas, entre elas essa imagem específica de um artista nacionalmente reconhecido pelos diferentes grupos sociais, teve a intenção de contribuir para o alargamento do que se denomina memória social.

As revistas ilustradas de época vêm a ser o principal objeto de estudo, que ainda incorpora os relatos orais e sua narrativa foto jornalística, trazendo em seu bojo memórias de vida e profissionais, além das contribuições de artigos de opinião, manifestos, boletins de associações, fóruns de debate que complementam as fontes orais na apreensão da experiência fotográfica contemporânea (Mauad, 2008).

Os pesquisadores na área da imagem precisam ter uma observação de qualquer representação gráfica apurada para poder decodificá-la e compreendê-la a partir de suas proposições temáticas, de seus suportes materiais, da habilidade e do savoir-faire dos seus produtores. Há metodologias para tal empreendimento, mas qualquer que seja a nossa opção metodológica é necessária uma boa fundamentação para essa decodificação e compreensão, com a acuidade na interpretação dos documentos imagéticos sendo realizada de forma tão delicada e séria quanto os métodos utilizados para divulgar o verbo silenciado no documento textual que podem trazer à tona os "não ditos" encontrados nos depoimentos dos sujeitos.

Para a análise do fac símile (Figura 5) foi utilizada a matriz de análise adaptada em virtude de a origem das imagens virem da imprensa com base em dois conceitos da semiótica: plano de expressão e conteúdo (Fonseca \& Porto, 2010).

\begin{tabular}{|l|l|}
\hline $1 . \quad$ Dados de Identificação \\
\hline Local do acervo & $\begin{array}{l}\text { Acervo da ABIA (Associação Brasileira } \\
\text { Interdisciplinar de Aids). Centro da cidade do } \\
\text { Rio de Janeiro. }\end{array}$ \\
\hline Nome da revista/jornal & Revista Veja (Editora Abril) \\
\hline Ano de publicação & 1989 (Ano 23, número 17) \\
\hline Números de exemplar & Edição 1.077 \\
\hline Página que se encontra a imagem fotográfica & Capa \\
\hline Data de publicação do exemplar da revista & 26/04/1989 \\
\hline Título ou manchete que acompanha & $\begin{array}{l}\text { Título: “Cazuza. Uma vítima da Aids agoniza em } \\
\text { praça pública”. }\end{array}$ \\
\hline
\end{tabular}

Figura 1 - Matriz de análise (dados de identificação). Fonte: Elaboração pelos autores. 


\begin{tabular}{|l|l|}
\hline 2. Dados para o Plano de Expressão & $\begin{array}{l}\text { Cazuza: Foto de Sérgio Zallis. } \\
\text { Ulisses Guimarães: Foto João Ramid. }\end{array}$ \\
\hline Crédito da imagem fotográfica & $\begin{array}{l}\text { Fotorreportagem } \\
\text { (Jornalistas: Alessandro Porro (Editor) e Ângela } \\
\text { Abreu). }\end{array}$ \\
\hline Relação texto imagem. & $\begin{array}{l}\text { Legenda inferior: “Cazuza. Uma vítima da Aids } \\
\text { agoniza em praça pública” } \\
\text { Legenda superior: “O PMDB em xeque-mate”. }\end{array}$ \\
\hline Legenda da imagem fotográfica & $\begin{array}{l}\text { Divulgação da aids como processo patológico } \\
\text { que atinge a todas pessoas indistintamente de } \\
\text { classes sociais e o contexto político pós- } \\
\text { constituinte. }\end{array}$ \\
\hline Resumo do texto & $\begin{array}{l}\text { Foto do Cazuza- posada, para a lente da } \\
\text { objetiva, como close. } \\
\text { Foto do Ulisses Guimarães- Flagrante. }\end{array}$ \\
\hline Formato de foto & $\begin{array}{l}\text { Cazuza - irregular } \\
\text { Ulisses - triangular }\end{array}$ \\
\hline Plano & $\begin{array}{l}\text { Cazuza - em primeiro plano. } \\
\text { Ulisses Guimarães - plano detalhe. }\end{array}$ \\
\hline Sentido Fotográfico & $\begin{array}{l}\text { Cazuza -Vertical } \\
\text { Ulisses Guimarães-Vertical }\end{array}$ \\
\hline Localização da imagem na página & $\begin{array}{l}\text { Cazuza: centro ótico e centro geométrico } \\
\text { (zonas 5 e 6). } \\
\text { Ulisses Guimarães - zona primária } \\
\text { principal (zona 1). }\end{array}$ \\
\hline
\end{tabular}

Figura 2 - Matriz de análise (plano de expressão). Fonte: Elaboração pelos autores.

\begin{tabular}{|c|c|}
\hline $\begin{array}{l}\text { Local retratado } \\
\text { O local retratado é o cenário da fotografia. }\end{array}$ & $\begin{array}{l}\text { Cazuza - sua residência. } \\
\text { Ulisses - Não identificado. }\end{array}$ \\
\hline $\begin{array}{l}\text { Fundo retratado } \\
\text { Fundo retratado: natural ou artificial e interno ou externo; }\end{array}$ & $\begin{array}{l}\text { Cazuza- retratado em espaço interno e natural } \\
\text { Ulisses Guimarães-sem condições de } \\
\text { avaliação. }\end{array}$ \\
\hline Pessoas retratadas & Cazuza e Ulisses Guimarães - individuais \\
\hline Tema das imagens retratadas & $\begin{array}{l}\text { Cazuza - Aids } \\
\text { Ulisses - político }\end{array}$ \\
\hline Atributos Pessoais & $\begin{array}{l}\text { Cazuza: usa óculos com lentes translúcidas. } \\
\text { Camisa escura sem gola e de mangas } \\
\text { compridas. Braços cruzados na frente do tórax, } \\
\text { apoiando as mãos nos ombros. Braço esquerdo } \\
\text { se sobrepõe ao direito. } \\
\text { Ulisses Guimarães: Veste terno escuro, com } \\
\text { gravata e camisa clara. }\end{array}$ \\
\hline Atributos de paisagem & $\begin{array}{l}\text { Cazuza. Fundo: parede com nuances } \\
\text { em degradé. } \\
\text { Ulisses não se identifica o fundo. }\end{array}$ \\
\hline
\end{tabular}

Figura 3 - Matriz de análise (plano de conteúdo). Fonte: Elaboração pelos autores.

\section{Dados complementares obtidos de outra imagem fotográfica}

\begin{tabular}{|l|l|}
\hline Origem da informação & $\begin{array}{l}\text { Meio eletrônico (Internet). A revista pode ser encontrada na } \\
\text { íntegra no acervo disponível online. }\end{array}$ \\
\hline Informação complementar & Não se aplica \\
\hline
\end{tabular}

Figura 4 - Matriz de análise (dados complementares). Fonte: Elaboração pelos autores. 


\section{Resultados}

A seguir se encontra a imagem do fac-símile deste estudo para apreciação, reflexão, crítica e discussão desta matriz e sua imagem ícone que ficará disponível para outros estudos.

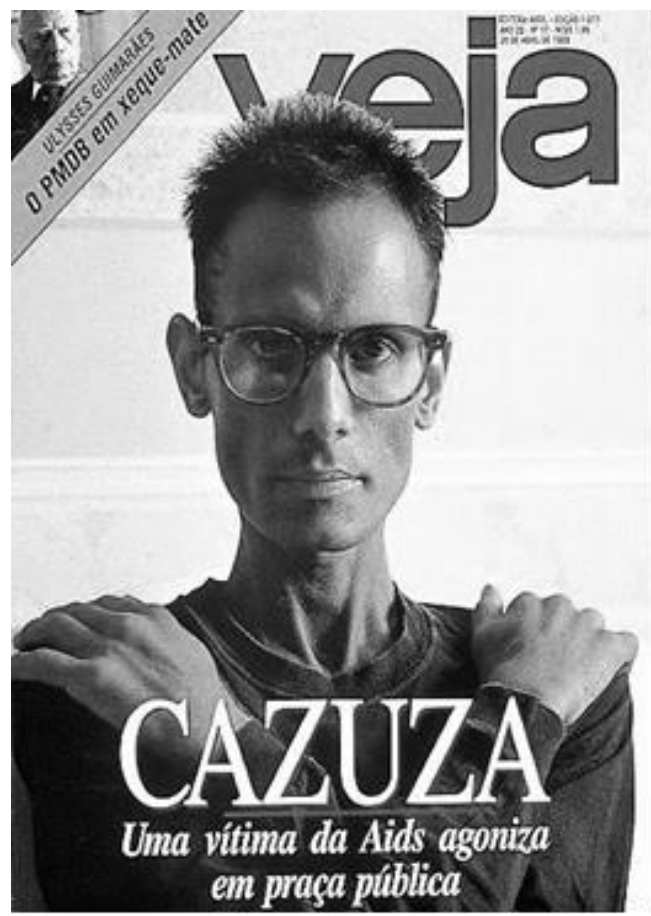

Figura 5 - Imagem de Cazuza como ferramenta de memória social. Fonte: Revista VEJA, 1989, capa. Editora Abril.

Trata-se de uma fotorreportagem, com duas imagens masculinas. Uma no centro de tamanho maior e outra menor na lateral esquerda. Possui legenda abaixo das imagens citadas com fotos. A legenda abaixo da foto do Cazuza tem o formato em três linhas. Já a abaixo da foto de Ulisses Guimarães tem formato de uma linha sintetizando as matérias. A foto do Cazuza é em primeiro plano, com sentido no centro da página. A de Ulisses Guimarães em plano detalhe. A imagem do Cazuza foi realizada em um cenário interno, tendo como fundo a parede de sua residência com nuances.

As manchetes da capa trouxeram a divulgação da aids como processo patológico que atinge a todas pessoas indistintamente de classes sociais, com Cazuza, contando como está enfrentando a aids, das crises pelas quais passou e seus sentimentos ao ser alvo de uma curiosidade ambígua: repleta de afeto, solidariedade, mas também de morbidez e sensacionalismo. Já Ulisses Guimarães, num contexto político pós-constituinte, participou de encontro de dois dias realizado em Brasília com onze governadores do PMDB. Esses governadores tentaram convencer o deputado a abrir mão de sua candidatura à sucessão do presidente José Sarney. A decisão tomada foi a aprovação de dois turnos para a escolha do candidato oficial do partido.

Pietroforte (2013) chama a atenção para a análise dentro de uma perspectiva semiótica alertando sobre a necessidade dos pesquisadores em imagem estarem atentos ao detalhamento das mesmas, usando lupa ou computador para identificar detalhes que podem ajudar a esclarecer pontos e ampliar a descrição proposta. Neste caso, por exemplo, 
a ampliação da imagem pode esclarecer o fundo da mesma, sendo evidenciada a parede da residência do retratado.

\section{Discussão}

O fac-símile em seu conteúdo jornalístico trouxe a declaração de que Cazuza tinha aids. A reportagem se encontra na página 80. Cazuza, ao utilizar ou ser utilizado pela mídia, fez brotar para os leitores a figura pública que deu cara à aids. Qualidades, comportamentos, atitudes e impulsos humanos estavam nele personificados. Emagrecimento extremo, deterioração física e internações frequentes eram informações associadas à imagem desse artista. Moscovici (2012) afirma que a imagem é personificada. Assertiva que se aplica à imagem de Cazuza.

A imagem do artista foi realizada em cenário interno, tendo como fundo a parede de sua residência com nuances. A manchete da capa divulgou a aids como processo patológico que atinge todas as pessoas, independentemente de classe social. Cazuza expôs como estava enfrentando a síndrome, as crises pelas quais passou e os sentimentos que o dominavam ao ser alvo de uma curiosidade ambígua, posto que repleta de afeto e solidariedade, mas também de morbidez e sensacionalismo.

O local retratado foi a residência do artista, fato que pode ser comprovado pelo texto a reforçar a identificação do local da imagem pelo próprio artista. Sua escrita, publicada como carta de repúdio, tem como título "Veja, a agonia de uma revista".

\footnotetext{
A leitura da edição da Veja, que traz meu retrato na capa produz em mim - e acredito que em todas as pessoas sensíveis e dotadas de um mínimo de espírito de solidariedade - um profundo sentimento de tristeza e revolta. Tristeza por ver essa revista ceder à tentação de descer ao sensacionalismo, para me sentenciar à morte em troca da venda de alguns exemplares a mais. Se os repórteres e editores tinham de antemão determinado que estou em agonia, deviam, quando nada, ter tido a lealdade a e franqueza de o anunciar para mim mesmo, quando foram recebidos cordialmente em minha casa. Mesmo não sendo jornalista, entendo que a afirmação de que sou um agonizante devia estar fundamentada em declaração dos médicos que me assistem, únicos, segundo entendo, a conhecerem meu estado clínico e, portanto, em condições de se manifestarem a respeito. A Veja não cumpriu esse dever e, com arrogância, assume o papel de juiz do meu destino. Esta é a razão de minha revolta. Não estou em agonia, não estou morrendo. Posso morrer a qualquer momento, como qualquer pessoa viva. Afinal, quem sabe com certeza quanto vai durar? Mas estou vivíssimo na minha luta, no meu trabalho, no meu amor pelos meus entes queridos, na minha música - e certamente perante todos os que gostam de mim" Cazuza (Nunes, 2010 p. 163).
}

Pellegrini (2013) afirma que o artista é um homem que experimenta as agruras e as doçuras da vida e, por conseguinte, não está alheio aos paradoxos da ambiência que o cerca. Portanto, seu labor e sensibilidade também não podem ser desagregados do mundo onde ele se insere. A carta do artista corresponde a sua inserção no mundo em que vivia e coloca sua indignação com a Veja ao afirmar que a revista assume o papel de juiz de seu destino.

Cazuza aceita a exposição na mídia com uma intencionalidade exposta posteriormente em sua carta resposta e acabou sendo ferido em seus valores, de forma multifacetada, afetiva e cognitiva, porém trouxe de forma indiscutível para sua imagem pública uma construção coletiva para as pessoas adoecidas pela aids.

Significativo lembrar que as representações sociais estabelecem uma construção coletiva, multifacetada e polimorfa, sendo proeminentes e representados os elementos cognitivos, afetivos, simbólicos e de valores que são determinados pelos sujeitos sociais em 
situações de intercâmbio com a realidade na qual convivem (Silva, Constantino \& Premaor 2011).

Na foto de Ulisses Guimarães, nesta mesma capa de revista, o local retratado natural não permite a identificação. $O$ fundo é neutro. $O$ político foi fotografado com o rosto franzido e olhar lateralizado para a esquerda. Tem como legenda: "O PMDB em xequemate". Veste um terno escuro, com gravata e camisa clara.

O fac-símile deste estudo (Figura 1) apresenta vestígio de interesse editorial não só na temática da aids e na vida do artista em apreço, mas, também, no contexto político do país, por meio da imagem de Ulisses Guimarães (Foto de João Ramid). A confeç̧ão da Constituição de 1988, mesmo tendo sido promulgada, ainda suscitava indagações e reflexões por parte da sociedade. Nesta capa a presença da imagem deste político chamava a atenção dos leitores para este processo do recorte temporal ainda em discussão e crítica, apresentando reportagem sobre o fato. Como Ulisses Guimarães foi um dos mais influentes legisladores brasileiros daquele momento e sendo este assunto de importância nacional, sua imagem serviu como referência. Posteriormente, a Edição 1.044, de 7 de setembro de 1988, com a manchete "Enlouquecidos pela liberdade", trouxe outra reportagem com esta figura pública fotografada, intitulada "O senhor Constituição" na qual não só era reconhecido o papel do deputado Ulisses Guimarães na condução do processo como também trazia uma análise dos prós e contras da Carta recém-finalizada. As virtudes democráticas da carta eram relacionadas, como também apontava a loucura que seriam os gastos e os direitos sem deveres instituídos, o que se tornaria um entrave ao crescimento do país.

As duas imagens associadas à imprensa na capa da Veja, de Cazuza e do político Ulisses Guimarães, podem ser consideradas fotografias públicas que ao serem visualizadas levam os leitores a encontrar na memória social situações vividas no passado. A fotografia pública pode ser compreendida segundo dois rumos: o da prática criativa e da expressão crítica do mundo visível. Pelo rumo da prática criativa a imagem é pensada como expressão autoral, colocando em questão o próprio princípio realista. Em relação à expressão crítica do mundo visível, a fotografia pública vem associada à imprensa ilustrada e a produção das notícias, agindo como janelas que se abrem para o mundo, concebendo-a da forma mais realista (Mauad, 2008).

É importante refletir sobre o papel ocupado pela imagem usando a fotografia pública nos processos de ajustamento do olhar na configuração do espaço público, o apelo que a mesma causa e a memória social que traz e lega para a sociedade. Acreditamos que essa imagem ícone apresentada aos sujeitos possa ter trazido da memória social do grupo, luz para o conhecimento do passado nas duas fases iniciais da manifestação da síndrome na cidade do Rio de Janeiro, delineando uma nova perspectiva para a prática cotidiana no presente.

Mauad (2008) corrobora o exposto ao defender que a fotografia se torna pública para cumprir uma função política que garanta a transmissão de uma mensagem para dar visibilidade às estratégias ou disputas de poder. A fotografia pública é produzida por agências de produção da imagem que desempenham um papel na elaboração de uma opinião pública (meios de comunicação, Estado, entre outros). São, portanto, o suporte de uma memória pública que registra, retém e projeta no tempo histórico uma versão dos acontecimentos. Essa versão é construída por uma narrativa visual e verbal, ou seja, intertextual, mas também multitemporal: o tempo do acontecimento, o tempo da sua transcrição pelo modo narrativo e o tempo da sua recepção no marco histórico da sua 
publicação, este último dimensionado pelas formas de sua exibição na imprensa, em museus, livros e projetos. A fotografia pública produz visualmente uma esfera pública nas sociedades contemporâneas, em compasso com as visões de mundo às quais se associa.

A capa da revista trazendo a fotografia pública de Cazuza e de Ulisses Guimarães, em consulta no sitio eletrônico do Google Imagens, se identificou com frequência de 230, sendo articulada a diversos temas, inclusive na língua estrangeira. A presença desta imagem que circulou por tantos sítios eletrônicos, nos leva ao princípio da circularidade da imagem selecionada. Com o auxílio dessa e de outras imagens existentes na mídia e selecionadas para a pesquisa como indutores de memória apresentados aos participantes foi possível não apenas (des) construir (pre) conceitos sobre o cuidado de Enfermagem à época, mas também analisar as repercussões desse cuidar no campo das representações sociais.

Delimitada a imagem de Cazuza na imprensa, trata-se de imagem posada do tipo close. O retratado aparentemente foi produzido para a foto, pois seus lábios estão brilhosos trazendo indícios de maquilagem. A imagem ampliada, possivelmente, por meio de ferramenta disponível por tecnologia própria, resultou também na captação do seu olhar altivo e fixo, "encarando" a lente da tecnologia que registrou sua imagem. "Encarar também pode ser interpretado como sinal de dominação. Isto pode ter se originado do comportamento primitivo, em que o olhar firme é uma tática de dominação" (Cohen, 2012, p. 53).

Destacam-se aqui alguns aspectos de interesse na construção do texto imagético, tais como cor da camisa em contraste com a coloração da pele de Cazuza e sua posição corporal. Seus braços estão cruzados na frente do tórax, apoiando as mãos nos ombros, tendo o braço esquerdo se sobrepondo ao direito. $O$ aspecto relacionado à sua posição corporal, de braços cruzados sobre o tórax, pode ter diversos entendimentos, dentre eles, corpo fechado contra o que a vida tinha de preconceito, e até mesmo dos agravos oportunistas à saúde. A posição dos membros superiores do artista abraçando a si mesmo quer dizer algo significativo. Para Cohen (2012, p. 52) "Muitos desses toques são auto confortantes ou autoprotetores. Se estou assustado, eu me abraço". As pessoas cruzam os braços defensivamente no mundo todo e, ao cruzarem os braços trata-se de uma tentativa de confortar-se. Na medida em que a imagem foi produzida com o consentimento do retratado, vivendo o desconforto da finitude do corpo emagrecido pela aids, estaria o artista tentando confortar-se?

A camisa ostentada por Cazuza é de cor escura, pode-se dizer na cor azul marinho, sem gola e de mangas compridas, o que contrasta com a coloração da pele. Esta coloração, independente das faces, pode-se identificar como escurecida, mesmo diante da luminosidade, sendo uma característica de pessoas que viviam com aids na época, apresentando aumento progressivo do ressecamento e escurecimento da pele pelo efeito de algumas drogas utilizadas.

Cabe ressaltar que a imagem foi feita sobre luz focal forte pelo brilho refletido na pele. Isto é dito, também, considerando as discretas sombras que contornam, em especial, o rosto, marcando em metade com claridade e a outra não. Nesta perspectiva, pode se inferir, pelo vestígio, a possível interpretação sobre as duas faces de Cazuza. Dito de outra maneira, a vida pública e a privada, por exemplo, como possibilidades que a mídia sugeriu construir e questionar. Este contraste, intencionalmente ou não, realça aspectos positivos e negativos. Isto implica que, apesar da capa da revista, em consulta simplificada no sitio eletrônico do Google, veicular a imagem, pela frequência de 230 (já mencionada anteriormente), ratifica-a como imagem ícone. 
O filósofo Charles Sanders Peirce afirma que os ícones imitam o objeto, representando a realidade em sua totalidade. Dentro da ótica deste filósofo, o ícone (neste caso a imagem em forma de fac-símile) representa um signo que indica um objeto (aqui está a "realidade") ao reproduzir ou imitar o mesmo. $O$ ícone tem com o objeto uma relação natural e se opõe à noção de indício (do fac-símile enquanto registro sobre algo do passado, por exemplo) e de símbolo (no qual aquilo que está representado de acordo com convenções socioculturais coletivas, ganha significado), sendo livre de intenções, apresentando-se como uma solidificação do real, com seu estudo ocorrendo por meio da semiótica da imagem (Peirce, 2000).

Mauad (2008) chama a atenção para a noção de foto-ícone, como sendo fotografia que pela conjugação de expressividade, conteúdo e contexto ganha uma face pública e se relaciona com a noção de acontecimento histórico.

Os aspectos negativos, possivelmente, em virtude da utilização de algum programa de modificação das imagens para apresentação ao público com a tecnologia disponível à época, ao mesmo tempo em que melhora e corrige falhas grosseiras ou não, filtra a realidade, mesmo considerando que ela se trata de representação, em especial, social, pela figura emblemática que ele representa/representava. Com efeito, ele se encontra morto biologicamente, mas vivo socialmente pelo impacto que tem nos dias atuais. Um exemplo disto é a existência da Organização Não-Governamental "Viva Cazuza".

Se o aspecto negativo pode ter virada positivo, o aspecto positivo foi torná-lo símbolo do combate contra aids, no sentido de desmitificar a contaminação em diversos situações. Ademais, potencializou a fama e visibilidade do artista na mídia, fazendo render, mesmo diante do protesto, lucros simbólicos até os dias de hoje.

A imagem divulgada pode reconstruir a realidade física das pessoas com aids para os diferentes grupos sociais a ela exposta, o que a enquadra como ferramenta de memória social dentro das representações. Segundo Jodelet (2001, p. 21), a teoria das representações sociais corresponde a "teorias espontâneas" formuladas coletivamente por grupos sociais que reconstroem a realidade em palavras e imagens.

Importante salientar que esta revista, em 1985 e em 1988, dedicou duas capas à aids. Esta reportagem trazendo a imagem de um ídolo da música brasileira (que morreria pouco depois, em julho de 1990) dividiu de forma crítica as opiniões manifestadas a respeito, levando a um novo patamar a discussão sobre a patologia no país. Dessa forma cabe salientar que mesmo com o destaque discutível da referida capa com a imagem de Cazuza e a manchete sensacionalista, a síndrome ficou em evidência, suscitando memória social, posicionamento, reflexões críticas e reações diversas para a temática.

\section{Conclusões}

A deterioração física de pessoas que viviam com o vírus HIV na década de 1980, propiciava fenômenos visuais específicos que contribuem e possibilitam edificações mentais ancoradas em fenômenos sociais, como é o fenômeno da aids. Essas edificações mentais, ancoradas em fenômenos sociais, são particularmente pertinentes à imagem do artista Cazuza, que se tornou uma imagem símbolo da aids presente em grande parte de pessoas que viviam com a doença em nossa população na década de 1980, quando os clientes tinham a "cara da aids". Conclui-se que a análise da matriz é ratificada como ferramenta de 
pesquisa de memória social imagética, podendo ser utilizada em estudos de representação social.

Trata-se, portanto, de uma ferramenta metodológica utilizável por pesquisadores de diversas áreas do conhecimento, inclusive a saúde e a enfermagem, que porventura venham a utilizar imagens em seus trabalhos e que tenham a noção de que estas são ambíguas e passíveis de interpretações múltiplas. Desta forma, é necessário um aprendizado do código que as decifre com a maior precisão possível e uma cautelosa discussão teóricometodológica que possa permitir a utilização com segurança em pesquisas no campo da representação social, no sentido de que a dimensão propriamente visual do real possa finalmente ser integrada aquilo que nos propomos a pesquisar.

Mesmo sabendo da existência de diferentes interpretações que uma imagem suscita e que podem ser encontradas na utilização de acervo imagético, estudos que utilizam imagens como recurso disponível para subsidiar o conhecimento devem ser estimulados. As imagens sendo representação social do olhar sobre um evento específico, que captura, permite em si a imagem do contexto, aceitando leituras e releituras daquilo que foi vivido e registrado pela lente de uma máquina (digital ou não), com diferentes interpretações, podem trazer ângulos diversos e aspectos da memória social inclusa na representação social imagética.

\section{Referências}

Andrade, M. C. S., \& Capocci, P. (2004). As emoções do profissional de enfermagem ao lidar com clientes com HIV/Aids. Revista de Enfermagem da UNISA, 5(1), 15-19.

Bardin, L. (2009). Análise de Conteúdo. Portugal: Edições 70.

Bauer, M. (2000). Análise de conteúdo clássica: uma revisão. In M. Bauer \& G. Gaskell (Orgs.). Pesquisa qualitativa com texto, imagem e som (pp. 189-217). Petrópolis: Vozes.

Brum, J. W. M., \& Mesquita, M. G. R. (2011). Epidemiologia do HIV/Aids. In J. L. Leite \& J. L. Leite (Orgs.). Aids: entre o biomédico e o social: pontos de partida e horizontes de chegada (pp. 67-78). Rio de Janeiro: Águia Dourada.

Ciavatta, M. (2006). Estudos comparados sobre formação profissional e técnica. In G. Frigotto \& M. Ciavatta (Orgs.). A formação do cidadão produtivo: a cultura de mercado no ensino médio técnico (pp. 117-136). Brasília: Instituto Nacional de Estudos e Pesquisas Educacionais Anísio Teixeira (INEP).

Cohen, D. (2012). A linguagem do corpo: o que você precisa saber (5a ed.). Petrópolis: Vozes.

Costa, T. L., Oliveira, D. C., \& Formoso, G. A. (2012). Representações sociais sobre pessoas com HIV/Aids entre enfermeiros: uma análise estrutural e de zona muda. Estudos e Pesquisas em Psicologia, 12(1), 242-259.

Fonseca, E. F. R., \& Porto, F. (2010). Fac-símile na pesquisa em história da enfermagem obstétrica. Inauguração da capela da Pró-Matre (1923). Revista de Pesquisa Cuidado é Fundamental Online, 4(2), 1495-1505. Recuperado de http://www.seer.unirio.br/index.php/cuidadofundamental/article/view/1315/pdf_236.

Galvão, J. (2000). Aids no Brasil: a agenda de construção de uma epidemia. Rio de Janeiro: Associação Brasileira Interdisciplinar de Aids (ABIA).

Gil, A. C. (2002). Como elaborar projetos de pesquisa (4ạ ed.). São Paulo: Atlas.

Guran, M. (1999). Linguagem fotográfica e informação. Rio de Janeiro: Editora Gama Filho.

Hornsey, M., Gallois, C., \& Duck, J. (2008). The intersection of communication and Social Psychology: Points of Contact and Points of Difference. Jornal of Communication, 58(4), 749-766.

Jodelet, D. (2001). Representações sociais: um domínio em expansão. In D. Jodelet (Org.). As representações sociais (pp. 17-44). Rio de Janeiro: EdUERJ. 
Leite, M. L. M. (1993). Retratos de Família: Leitura da Fotografia histórica. São Paulo: Editora da Universidade de São Paulo.

Mauad, A. M. (2008). Poses e flagrantes: ensaios sobre história e fotografia. Niterói: EdUFF.

Ministério da Saúde (2014). Boletim Epidemiológico DST/Aids. Recuperado em 10 de dezembro, 2014, de http://www.aids.gov.br/publicacao/2014/boletim-epidemiologico-2014.

Moscovici, S. (2012). A psicanálise, sua imagem e seu público. Petrópolis: Vozes.

Nunes, T. N. (2010). Cazuza: o caso da Veja 1.077 - Análise ética do discurso da revista Veja sobre a doença e morte de Agenor de Miranda Araújo Neto. Revista Brasileira de Ensino de Jornalismo, 1(6), 145-171.

Peirce, C. S. (2000). Semiótica (3a ed.). São Paulo: Perspectiva.

Pellegrini, S. C. A. (2013). O realismo social de Coubert: notas sobre as interfaces entre a pintura e fotografia na pesquisa histórica. Patrimônio e Memória, 9(2), 17-42.

Pietroforte, A. V. S. (2006). O sincretismo entre a semiótica verbal e visual. Revista intercâmbio, 15(s/n), 1-10. Recuperado de http://revistas.pucsp.br/index.php/intercambio/article/viewFile/3636/2378.

Pietroforte, A. V. S. (2013). Análise do texto visual: a construção da imagem. São Paulo: Editora Contexto.

Sá, C. P. (2005). As memórias da memória social. In C. P. Sá (Org.). Memória, imaginário e representações sociais (pp. 63-86). Rio de Janeiro: Museu da República.

Sá, C. P. (2012). A memória histórica numa perspectiva psicossocial. Morpheus - Revista Eletrônica em Ciências Humanas, 9(14), 94-103.

Silva, A. M. T. B., Constantino, G. D., \& Premaor, V. B. A. (2011). A contribuição da teoria das representações sociais para análise de um fórum de discussão virtual. Temas em psicologia, 19(1), 233-242. Recuperado de http://pepsic.bvsalud.org/scielo.php?pid=S1413-389X2011000100018\&script=sci_arttext. 